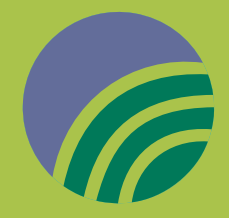

\section{Brongersma, Matias, Segalman, Shea, and Watanabe to chair 2013 MRS Spring Meeting}

www.mrs.org/spring2013

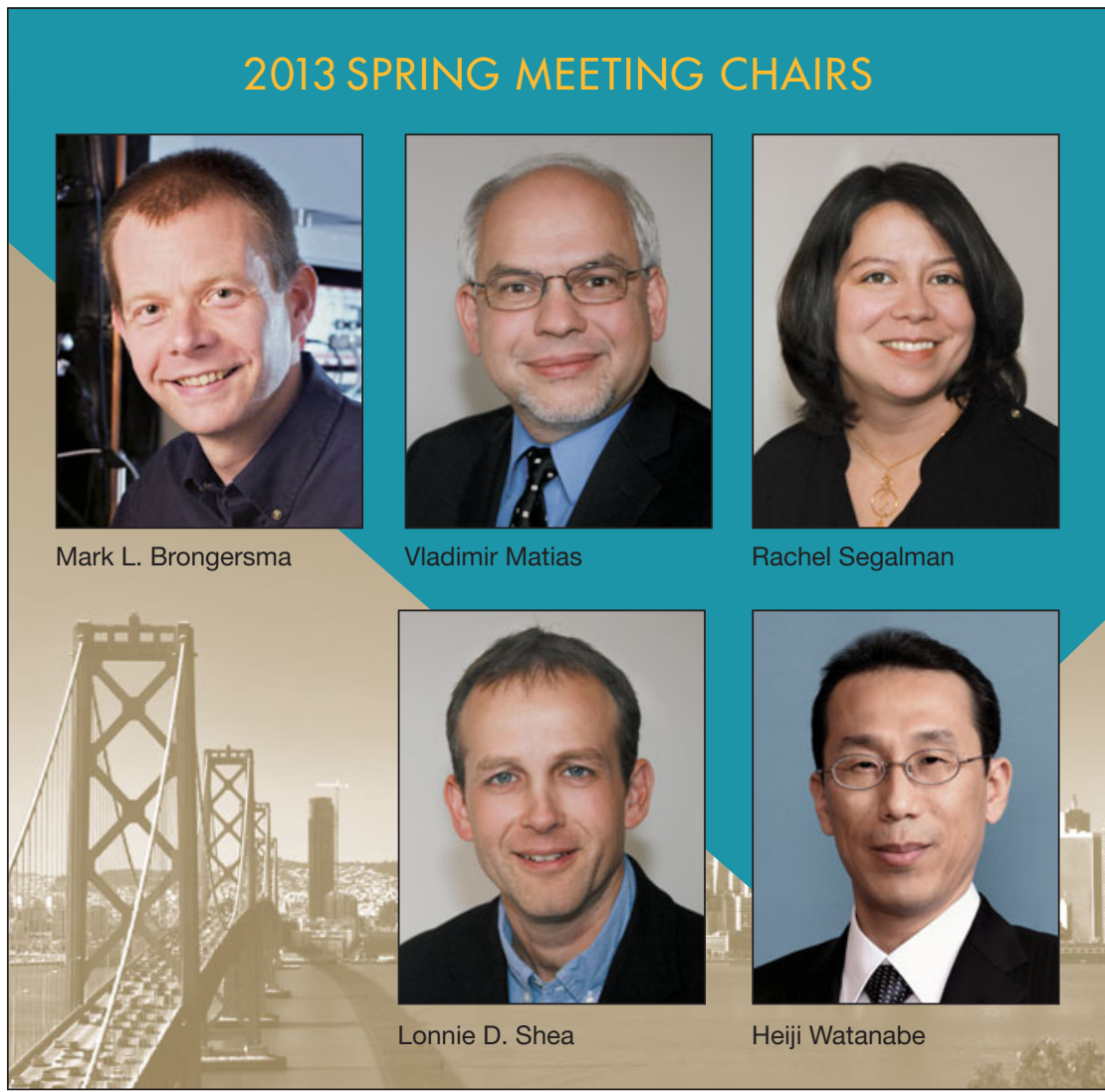

M eeting Chairs for the 2013 Materials Research Society (MRS) Spring Meeting are Mark L. Brongersma (Stanford University), Vladimir Matias (iBeam Materials, Inc.), Rachel Segalman (University of California-Berkeley), Lonnie D. Shea (Northwestern University), and Heiji Watanabe (Osaka University). The meeting will be held in San Francisco on April 1-5.

Mark L. Brongersma is an associate professor and Keck Faculty Scholar in the Department of Materials Science and Engineering at Stanford University. His most recent research focuses on Si-based light-emitting materials, light sources, modulators, detectors, and metallic nanostructures that can manipulate and actively control the flow of light at the nanoscale. He received his $\mathrm{PhD}$ degree in materials science from the FOM Institute in Amsterdam, The Netherlands, in 1998. From 1998 to 2001, he was a postdoctoral research fellow at the California Institute of Technology. He has over 100 publications and holds a number of patents in the area of Si microphotonics and plasmonics. Among his honors, Brongersma received a National Science Foundation CAREER Award, the Walter J. Gores Award for Excellence in Teaching, the International Raymond and Beverly Sackler Prize in the Physical Sciences (Physics) for his work on plasmonics, and he is a Fellow of the Optical Society of America, the SPIE, and the American Physical Society.

Vladimir Matias is team leader and project leader in the Superconductivity Technology Center at Los Alamos National Laboratory (LANL) since 2001. Prior to joining LANL, he was at Oxxel, Oxide Electronics GmbH (Germany) and at Conductus, Inc. (Sunnyvale, CA) where he worked as senior scientist and supervisor. He is currently involved in starting a new company called iBeam Materials, Inc., which intends to commercialize the process for ion-beam-assisted crystalline alignment in thin films. He has a BS degree (1983) from the California Institute of Technology and $\mathrm{PhD}$ degree (1991) from Stanford University, followed by a postdoctoral position at Delft University (The Netherlands). Matias has over 100 technical publications, including book chapters and review papers, and six patents issued and more pending. He has organized a number of technical conferences, including initiating three MRS symposia. His work at LANL has resulted in two R\&D Magazine R\&D 100 Awards in 2004 and 2010.

Rachel Segalman is an associate professor of Chemical and Biomolecular Engineering at the University of California (UC)-Berkeley and a faculty scientist in the Materials Science Division at Lawrence Berkeley National Laboratory. Her current research interests include controlling the structure and thermody-

MRS namics of functional polymers including semiconducting and bioinspired polymers, and in designing polymeric and hybrid materials for energy applications including thermoelectrics, photovoltaics, and solar fuels. She received her BS degree from the University of Texas at Austin. She then performed her doctoral work in chemical engineering (polymer physics) at the UC-Santa Barbara working with Edward J. Kramer, followed by a postdoctoral position at the Université Louis Pasteur in Strasbourg, France, working with Georges Hadziioannou on conjugated polymer synthesis. Segalman joined the faculty of UC-Berkeley in the spring of 2004 as the Charles Wilke Assistant Professor of Chemical Engineering and was 
promoted to Associate Professor in 2009. Among other awards, Segalman received the 2012 Dillon Medal from the American Physical Society and is an Alfred P. Sloan Fellow and a Camille Dreyfus Teacher Scholar. She is an associate editor for the Annual Reviews of Chemical Engineering and is on the Editorial Board of Macromolecules.

Lonnie D. Shea is a professor in the Department of Chemical and Biological Engineering at Northwestern University. He received his BS and MS degrees at Case Western Reserve University. He received his $\mathrm{PhD}$ degree in chemical engineering and scientific computing while working with Jennifer Linderman at the University of Michigan, and was a postdoctoral fellow with David Mooney in the Dental School at the University of Michigan. Shea joined the faculty at Northwestern in 1999 and established a research group working at the interface of tissue engineering, gene therapy, and drug delivery. He received an NSF CAREER Award in 2000, which helped start the work on developing new technologies based on combining biomaterials and gene/drug delivery. In his laboratory, materials researchers work with clinical collaborators throughout the medical school. Shea is also director of the NIH Biotechnology Training Grant at Northwestern University. He is a Fellow of the American Institute of Medical and Biological Engineering, and is a member of the editorial boards for Molecular Therapy, Biotechnology and Bioengineering, and Drug Delivery and Translational Research.

Heiji Watanabe is a professor with the Graduate School of Engineering at Osaka University and the director of the Research Center for Ultra-Precision Science and Technology. His current research interests include metal/high-k gate stacks, high-mobility Ge devices, $\mathrm{SiC}$ power electronics, and bionanotech- nology utilizing the protein ferritin. $\mathrm{He}$ received his $\mathrm{BE}$ and $\mathrm{ME}$ degrees from Osaka University in 1988 and 1990, respectively. In 1990, he was with NEC Corporation, Tsukuba, where he engaged in research on nanofabrication technology using beam-induced surface reactions. $\mathrm{He}$ received his $\mathrm{PhD}$ degree in electronic engineering from Osaka University in 1994. From 1994 to 1998, Watanabe joined the Atom Technology Project carried out by the Joint Research Center for Atom Technology (JRCAT). Upon returning to NEC Corporation, Watanabe worked on the research and development of high-k gate dielectrics. He joined the faculty at Osaka University in May 2004. Watanabe has published more than 170 scientific papers. He received several awards, including the Japan Academy Medal and Japan Society for the Promotion of Science (JSPS) Prize in 2011.

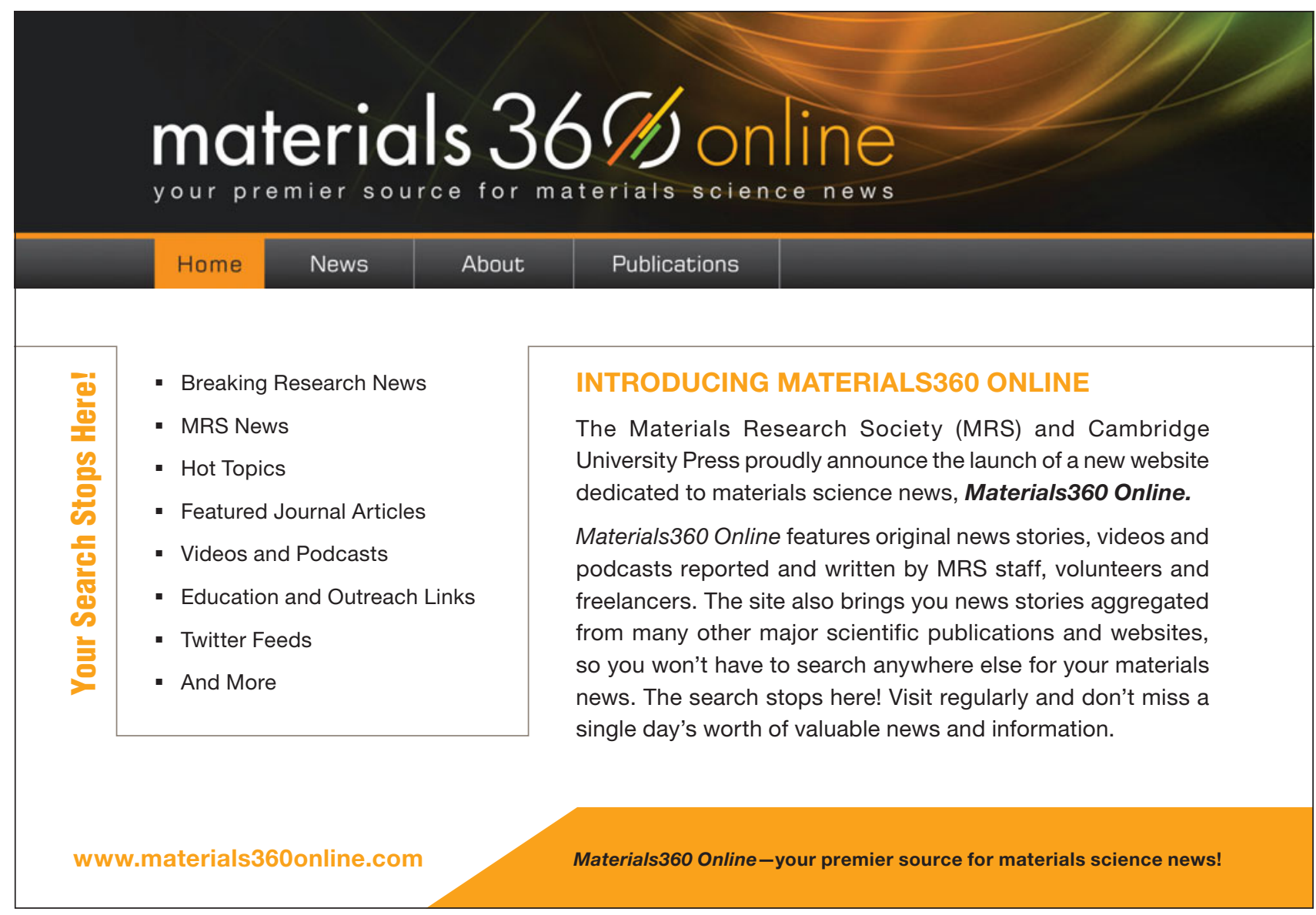

